\title{
Jumping the smoking gun
}

\section{Are antibiotics in animal feed a threat to human health? Contrary to some opinions, the latest evidence put forward in the United States is inconclusive.}

\begin{abstract}
AlTHOUGH Western Europe has now banned the use of antibiotics as a growthpromoting additive in animal feeds, the United States has since 1977 - when a proposed ban was blocked by Congress maintained that additional data are needed to justify such an action. Half of the 35 million tons of antibiotics manufactured each year in the United States end up in animal feed; not surprisingly, the prospect of a ban is not looked upon favourably by the pharmaceutical industry.
\end{abstract}

But neither is it by farmers. The evidence, as paradoxical now as it was when the growth effect was discovered in 1949 , is nonetheless convincing that chickens, pigs and cattle do much better when fed subtherapeutic doses of antibiotics. Even when the animals show a significant percentage of resistant bacteria in the gut, the effect persists; chickens, for example, will gain weight as much as 10 per cent faster when fed antibiotics ${ }^{1}$.

Balanced against this convincing economic benefit, however, is mounting concern about the spread of resistant organisms. The discovery that resistance can be conferred by mobile plasmids, and the appearance of certain resistant strains of gonorrhoea, Haemophilus influenzae and dysentery-causing organisms, has led to repeated calls for cutting back "inappropriate" use of antibiotics; a prime target is their use in animal feeds. The case has always been circumstantial: although it is known that resistance-conferring plasmids do occur in animal-borne microorganisms and that plasmids can readily be transmitted to other bacteria, there has been a lack of convincing proof that the end result actually is the production of resistant strains of human pathogens. A major complication in any effort to establish such a link is the other half of the US antibiotic production, the half that ends up in humans, not infrequently for reasons that range from the inappropriate (ingrown toenails) to the unethical (as placebos for treating colds).

Now, proponents of a ban claim to have found the smoking gun. A study published last month in the New England Journal of Medicine ${ }^{2}$ traces an ampicillin-carbenicillin-tetracycline-resistant salmonella infection in 18 persons to a beef cattle herd that was the probable source of hamburger eaten by at least 13 of the patients. The cattle had been fed subtherapeutic amounts of chlortetracycline; no therapeutic doses had been administered. The bacteria in all of the patients showed identical resistance and contained a 38-kilobase $R$ plasmid; and these bacteria were identical with salmonella isolated from the tissue of a dairy calf that died of scours on a farm adjacent to the beef feedlot. No samples of hamburger were tested, however. In an editorial in the same issue of $N E J M^{3}$, Stuart Levy of Tufts University, a longtime critic of the use of antibiotics in animal feed, asserts that this study establishes an "important missing link", and concludes that "the clarion is strong and clear".

But the clarion may sound differently, depending on where one is sitting. Salmonella is one of the few pathogens common to animals and humans; it is facile to point to this case as proof that subtherapeutic antibiotics in animals can lead to antibiotic-resistant diseases in humans. Salmonella is a dangerous organism whether it is resistant or not. It should never be present in meat, whether it is resistant or not. Treatment of salmonellosis does not involve the use of antibiotics. The entire story makes a stronger case for ensuring proper sanitation in meat processing and for cooking your hamburger than it does for banning antibiotics in cattle feed.

Even more to the point, 12 of the 18 patients had been taking antibiotics, most for questionable reasons, when they became ill. Three had taken the drugs without the direction of a physician, using pills left over from an earlier prescription or from a family-member's prescription; the others had had them prescribed for sore throats or bronchitis. Because the gastrointestinal symptoms appeared very rapidly after the patients began taking the drugs (usually a matter of 1-2 days), it seems likely that they already had an asymptomatic infection that flourished as soon as competing, non-resistant bacteria were wiped out by the antibiotics. The important conclusion that cannot be overlooked is that if those concerned had not been taking the drugs - and most of them probably should not - they would not have become ill. (Much is being made of the fact that one of the 18 patients died. According to the authors, he received his infection from an incompletely disinfected sigmoidoscope that had just been used on one of the salmonellosis patients.)

Rather than a "compelling" case for the banning of antibiotics from animal feed, as Levy would have it, the study begs the question whether animals are a significant generator of resistant human pathogens. Just as it has been insufficient merely to lay out the theoretical possibility that resistance in animal bacteria could be transferred to human pathogens (a possibility that no one disputes), so it is insufficient to demonstrate, however elegantly, that meat contaminated with resistant salmonella can make people ill. The real question is the extent to which resistance engendered in animal bacteria is responsible for the spread of resistance to strictly human pathogens, such as gonorrhoea. Levy's argument that we have to worry more about antibiotics fed to animals than antibiotics fed to humans because animals produce more faeces is unconvincing. The real missing link is the extent to which human pathogens have an opportunity to interact with animal pathogens and to acquire resistance plasmids. This is surely the limiting factor in determining the animal-feed contribution to resistant human pathogens. Speaking vaguely about the "environmental pool" of resistance plasmids makes little sense in the absence of an answer to this question.

One recent attempt to look at the big picture in fact suggests that there are mechanisms in the environment that indeed limit the spread of resistance. Barbara Atkinson and Victor Lorian have reviewed tests for resistance made on $43,250,000$ bacterial samples in 242 hospitals from 1971 to 1982 and have found no overall increase in resistance to 15 different antibiotics during this period ${ }^{4}$.

Indeed, the very fact that none of the bacteria residing in the gut of farm animals is resistant suggests that some equilibrium has been reached. If, in a couple of hundred thousand generations, bacteria have not become totally resistant in the face of assault by subtherapeutic antibiotics, is it merely complacency to assume they never will? It seems plausible that the energy cost to the bacteria of maintaining resistance plasmids is at least one countervailing force in the equilibrium equation.

If nothing else, all this should convince us that we do not risk imminent disaster by delaying regulatory action until we understand better the spread of resistance plasmids. Stephen Budiansky

Dafwang, I.I., Bird, H.R. \& Sunde, M.L. Poultry Sci. 63, 1027-1032 (1984)

2. Holmberg, S.D. et al. New Engl. J. Med. 311, 617-622 (1984).

3. Levy, S.B. New Engl. J. Med. 311, 663-665 (1984). 4. Atkinson, B.A. \& Lorian, V. in Am. Soc. Microbiol. Meet.

7 March (1984); also J. clin. Microbiol. (in the press). 